\title{
Collaboration between General and Special Education Teachers in Inclusive Classrooms: A Review of the Literature
}

\author{
Maria Mouchritsa $^{1 *}(\mathrm{PhDc})$ Spyridon Kazanopoulos ${ }^{1}(\mathrm{PhDc})$ Ainara Romero ${ }^{2}(\mathrm{PhDa})$ \\ Urza Garay $^{3}(\mathrm{PhD})$ \\ 1. University of the Basque Country, UPV/EHU, Spain \\ 2. Department of Didactics and School Organization, University of the Basque Country, UPV/EHU, \\ Leioa (Bizkaia), Spain \\ 3. Department of Didactics of Language and Literature, University of the Basque Country, UPV/EHU, \\ Leioa (Bizkaia), Spain \\ * E-mail of the corresponding author: mmouchritsa001@ikasle.ehu.eus
}

\begin{abstract}
Teaching in inclusive classrooms is challenging for teachers, therefore, collaboration is considered one of the main elements for inclusive education to be effective for all students. This paper aims to conduct a literature review of how general and special education teachers implement collaborative practices to meet all students' needs in mainstream schools. Peer-reviewed academic papers and dissertations on collaborative practices were reviewed. The literature review offers an analysis of studies that address how teachers collaborate in the context of inclusive classrooms. The resultant discussion indicates that teachers recognize the value of collaboration but they highlight insufficient and limited collaborative behavior. The review also shows that there is a difference between studies regarding the implementation of collaborative practices and this can be interpreted by the different school cultures in each research. Nevertheless, this paper illustrates a variety of obstacles, which hinder the teachers' partnership and pinpoint the need for specific factors as training, positive attitudes, communication, and more time for the collaboration between teachers to be successful. Finally, this review demonstrates the need for additional research to fill the remaining gaps concerning the development of methods to overcome constraints impeding successful collaboration.
\end{abstract}

Keywords: inclusive education, collaboration, general - special education teachers, obstacles.

DOI: $10.7176 / \mathrm{JEP} / 12-6-04$

Publication date: February $28^{\text {th }} 2021$

\section{Introduction}

Inclusive education gives students with special education needs access to learn beside typically developing peers in the general classroom, with the required support from special and general educators who collaborate to plan for students' needs (Downing \& Peckham-Hardin, 2007). A significant role in supporting inclusive education is therefore performed by collaboration, reciprocity of experiences, school partnerships, and developing positive relationships between all members of the educational process (Mặrgặriţoiu, 2010). Thus, this paper explores collaboration practices that teachers implement in inclusive classrooms to meet students' special education needs.

There are many ways teachers can collaborate. One way is through curricular co-planning. Moreover, general education teachers should share their lesson plans with the special education teacher for the special education teacher to arrange feedback and adjustments, which may benefit students with special education needs. Therefore, the general education teacher must be prepared with weekly plans, while the special education teacher must be deeply informed about student's Individualized Education Program (IEP) goals and be aware of needed adaptations and interventions. Ideally, special education teachers can enhance curricular adaptations for students with and without special education needs, planning lessons accessible to all students (Solone et al., 2020).

Furthermore, a good inclusive practice that reflects collaboration between general and special education teachers is co-teaching. Co-teachers plan, teach, and evaluate lessons together, working as collaborators on every feature of teaching. Several co-teaching modifications have been discussed (Friend et al., 2010). These different approaches include: one teach, one observe, where one teaches the class while the other observes; one teach, one assist (or 'drift'), where one teaches, and the other walks around the classroom to discreetly provide individual support as needed; station teaching, where co-teachers provide instructions to students at different learning stations; parallel teaching, where each teacher instructs half of the class in the same or similar content; alternative teaching, where one teaches most students and the other one works with a smaller group and provides specialized instruction; and team teaching (or interactive teaching), where both co-teachers share teaching responsibilities equally and lead the instruction in class collaboratively (Friend et al., 2010). This review might provide a more comprehensive investigation into the efficiency of the collaborative practices that educational team members implement in the context of inclusive education.

Nevertheless, cultures that have adopted an inclusive educational system still face a variety of constraints when it comes to implementing inclusive practices including collaboration between teachers. Collaboration 
undergoes several obstacles including insufficient training for both general and special education teachers (Conderman \& Johnston-Rodriguez, 2009), insignificant school support for collaboration, insufficient assigned time for collaboration, strained relations between teachers in the classroom, and inadequate sharing of responsibilities (Hamilton-Jones \& Vail, 2013). Therefore, this paper aims to provide an insight into these obstacles and pinpoint factors that can ensure the implementation of successful collaborative practices.

A study reveals that teachers' experiences with inclusive school settings and their attitudes towards team working have a high impact on the collaboration between them (Hellmich et al., 2017). Furthermore, teachers report the need for training. General and special education teachers to be effective in their collaboration and implement successful co-teaching methods also need to develop a reliable relationship (Friend et al., 2010; Pratt, 2014). Moreover, co-teachers who agree on daily tasks, their roles and obligations, and their perspective of teaching in inclusive classrooms can build a collaborative relationship (Pratt, 2014; Rytivaara et al., 2019).

Thus, this review covers collaborative practices that have been implemented among general and special education teachers in inclusive classrooms to enhance students' potential as much as possible and meet different interests, profiles, and needs. Furthermore, obstacles, which hinder the teachers' partnership and pinpoint the need for specific factors for the collaboration between teachers to be successful are recorded. Finally, the main goal of this paper is to fill the remaining gaps in knowledge concerning the development of methods to overcome constraints impeding successful collaboration.

\section{Sources of Information}

Various databases were utilized in the research for this literature review: Educational Resource Information Center (ERIC), Google Scholar, Scopus, ProQuest Dissertations \& Theses, and Greek database of doctoral dissertations. This review focused on the academic research literature in peer-reviewed journals and dissertations. The articles included in this literature review were published between 2010 and December 2020. The keywords searched contained separate or combined searches of the following terms: Collaboration, cooperation, collaborative practices, co-teaching, collaboration in teaching, cooperation in teaching, teachers' partnerships, special education, and general education teachers, inclusive education, inclusion, inclusive classrooms, special education, and co-educating, constraints, obstacles, barriers.

\section{Content and Way of Collaboration}

Reviewing the literature devoted to the content and the way of collaboration between general and special education teachers, as per findings, Bouillet (2013) was the first to conduct a research on primary schools and investigated the most important aspects of collaboration between general and special education teachers (rehabilitators) in primary schools in Zagreb and Zagrebačka County. Questionnaire and interviews revealed that individual work with students and solid assistance to teachers were the main dimensions of their collaboration. Moreover, some teachers highlighted the importance of rehabilitators, when they work with parents of students with special education needs (SEN), and during the development of individual educational curriculum. Three teachers also emphasized that special education teachers help them by working in special classes with students with SEN. Generally, teachers would like to participate in teamwork and improve the level of collaboration, which would benefit all participants in the process of inclusive education.

Investigating the cooperation between the general and special education teachers, Mavropalias (2013) carried out mixed-method research, which showed that the level of cooperation for most teachers is not satisfactory. Special education teachers who work at Parallel Support in Greece stressed that they cooperate with general teachers in the cognitive and social-emotional field of the child, in subjects of classroom management, in issues concerning the curriculum, and service matters. However, concerning the co-planning of the teaching, the collaboration of co-teachers, and the goal they set was focused on one or two children with special educational needs and not on a larger group of students. Additionally, during co-teaching, the co-teachers were "cut off" from each other. The general education teacher had the main responsibility of teaching the content based on the curriculum and the special education teacher supported the child with a disability. Also, the special education teachers stated that they do not feel completely equal with the general education teacher nor do they co-decide equally with him on issues regarding class operation.

Al-Natour et al. (2015), also examined teachers' practices of collaboration in four domains, pre-referral and referral, evaluation and diagnosis, program planning, and program implementation. A mixed-method (questionnaire and interviews) was chosen and the results revealed that collaboration between general and special education teachers in Jordan is insufficient in span and frequency. The referral process is considered as an individual act and is limited to the exchange of information about the students who need to be referred to the resource room. Moreover, teachers asserted that communication and cooperation for the students' assessment are constrained because they believe that special education teachers are responsible for this process and retain the required knowledge which is inadequate for general education teachers. Additionally, at the stage of planning and implementing students' educational programs, teachers postulated that they do not collaborate as this 
procedure is special education teachers' duty. Even though some teachers stated having collaboration with each other, the actions they indicated as examples of their collaboration, when closely examined, do not include both of them working together and therefore can hardly be considered as collaboration.

Results from a study in Malaysian schools (Khairuddin et al., 2016) brought to light that collaboration between general and special education teachers is limited to educate students with special education needs. Special education teachers for mixed-method research stated that they had positive and reciprocally respectful communication with their general education colleagues. Nevertheless, the interaction between them is constrained regarding individual programs or learning activities for students with special education needs.

To effectively assess important collaborative practices, a mixed method research (Mulholland \& O'Connor, 2016) composed of questionnaires and semi-structured interviews was performed to explore the collaborative practice between Classroom Teachers (CTs), Learning Support Teachers (LSTs), and Resource Teachers (RTs) in mainstream classrooms in Ireland. All teachers stressed that collaboration with each other is a fact and considered it a very crucial dimension of their teaching. Additionally, collaboration is urged within schools using guidelines on collaborative practice. Teachers also pointed out that current plans for collaboration were mainly positive, with teachers recognizing the special knowledge each can offer through interactions.

Discussing the aspects of collaborative practices, a qualitative study (Bešić et al., 2017) in Styria with semistructured expert interviews showed that cooperation between general and special educators differed from school to school and team to team. Moreover, cooperation and joint planning of lessons were not consistently organized or scheduled. Furthermore, teachers discussed lesson goals, methods, performance, and development of students along with assessment exchanged ideas and solutions for various problems and defined guidelines between themselves. Even though they co-planned and were responsible for all students, simultaneously they stated a clear delimitation of their roles.

Zagona et al. (2017) also conducted mixed-method research (survey and interviews) in the Western United States which revealed the importance of the relationship between special and general educator and three skills connected with collaboration: participating in Individualized Education Program (IEP) teams, sharing responsibility for decision making, and working with other professionals to plan for the implementation of IEP goals and objectives. Additionally, special educators stressed that they felt more prepared to collaborate with their colleagues, as compared with general teachers.

Conversely, results from research conducted in Greece (Papanikolaou, 2018) showed that general and special education teachers do not co-teach nor do they share the responsibilities of the lesson, they do not jointly assess the performance of the students, as well as they do not evaluate the effectiveness of their teaching. Furthermore, teachers collaborate mainly concerning students with special education needs. In contrast, teachers rarely collaborate to implement activities for all students and manage behavioral problems in the class.

An interesting approach to collaboration practices has been proposed by Ghedin and Aquario (2020). The study is constructed by an exploratory phase (observations and survey) and a phase that includes a workshop. Observation results indicated an insufficient level of collaboration between special and general educators in Italian mainstream schools. Besides, a collaboration concerning instruction and assessment resulted in more beneficial and expansive, while collaboration about student work and classroom management was limited. As shown by the observation of the co-taught classroom after the workshop on collaboration, teachers can implement those factors which allow them to generate a shared assessment and management of the class to meet students' different profiles and needs.

An empirical research project (Semon et al., 2020) utilized recorded occurrences of team teaching approach data and survey data from the coaches and special education teachers in West Central Florida showed that the most common co-teaching model was 'one teach, one assist'. The 'Parallel teaching' approach was also frequently used during the data collection period. Nevertheless, throughout the study, a slight increase in multiple coteaching approaches is highlighted.

Jurkowski et al., (2020) studied general and special education teachers' individual experiences regarding coteaching in German secondary schools and showed three forms of collaboration on the level of teaching dyad. First, co-instructors interviewed stressed that they exchange information and materials in preparation of lessons. Second, the teachers mentioned shared planning of assignments, and third, co-teachers stated that they work together and jointly prepare, implement, and assess lessons and exercises in the context of co-construction.

In a recent paper by Kirkpatrick et al. (2020) resource and classroom teachers participated in a pilot project in Ontario and close to the end of the school year they completed questionnaires to evaluate the nature of their collaborative practices. Both of the teachers stressed that out of the classroom they co-plan lessons and assessments, get resources, and discuss students' peculiar needs. Furthermore, resource teachers highlighted aspects as finding resources, marking and assessing diagnostics, and examining models of co-teaching. Moreover, classroom and resource teachers indicated similar instructional practices in the class. The model of 'one teaching, one drifting', was mostly applied while 'parallel teaching' was rarely utilized. In contrast, resource teachers stated more frequent use of team teaching than classroom teachers 


\section{Obstacles}

A recent review of the literature on the obstacles which tend to decrease the level of collaboration between general and special education teachers found that time - based barriers is a crucial factor that impedes the frequent implementation of co-teaching practices (Mulholland \& O'Connor, 2016; Papanikolaou, 2017; Semon et al., 2020). Similarly, Al-Natour et al. (2015) and Bešić et al. (2017) and Ghedin \& Aquario (2020) and Jurkowski et al. (2020), and Kirkpatrick et al. (2020) outlined time constraints, since schools do not stipulate an allocated time for co-teachers concerning shared planning of teaching and assessment.

It is of interest that Kirkpatrick et al. (2020) has presented the challenge of balancing teachers' partnership with their other responsibilities, such as parent meetings and unexpected occurrences that are required. Moreover, Bešić et al. (2017) highlighted that special educators saw their weekly high workload as a challenge, which creates a stressful environment and hinders teachers' collaboration. Al-Natour et al. (2015) also pointed out the enormous teaching and administrative workload assigned to teachers as a dominant constrain towards achieving collaboration.

Another main obstacle of teachers' collaboration is the insufficient knowledge regarding students with special education needs as noted by general educators (Papanikolaou, 2017). Besides, several authors (Kirkpatrick et al., 2020; Mayropalias, 2013; Mulholland \& O'Connor, 2016) brought to the light limited professional development opportunities and extra-curricular support as major co-teaching barriers. Moreover, Jurkowski et al. (2020) found that teachers' partnerships confront the lack of specifications for shared class leadership, while Al-Natour et al. (2015) described the shortage of awareness among general education teachers concerning the importance of collaboration as a barrier to implementing co-teaching.

Semon et al. (2020) and Jurkowski et al. (2020) have demonstrated that the lack of resources as teaching materials to meet the students' special education needs and workspaces for co-teachers impede their collaboration. Furthermore, Mayropalias, (2013) and Papanikolaou (2017) and Ghedin \& Aquario (2020) described that special education teachers often act as assistants in the classroom, creating an imbalance in the use of expertise and skills and focusing on students with special education needs, which creates conflicts among teachers and hinders their partnerships.

Moreover, collaboration encounters challenges such as existing perceptions of the classroom and resource teacher relationship (Kirkpatrick et al., 2020). Zagona et al. (2017) revealed that educators are feeling less prepared to collaborate with colleagues who have different philosophies about collaborating and supporting students with significant disabilities. Another equally important obstacle is that personality and teaching style differences hinder the effective and frequent collaboration between teachers (Papanikolaou, 2017; Semon et al., 2020).

Examining the constraints underlying the lack of teachers' collaboration, Jurkowski et al. (2020) pointed out the shortage of principals' leadership skills. Consequently, several authors (Al-Natour et al., 2015; Mayropalias, 2013; Semon et al., 2020) showed that lack of administrative support within the school system affects negatively co-teachers' aspects of collaboration.

\section{Factors for Successful Collaboration}

To overcome partnerships' constraints, it is necessary to adopt a variety of factors for teachers' collaboration to be successful. In related references (Jurkowski et al., 2020; Khairuddin et al., 2016; Mayropalias, 2013; Zagona et al., 2017) it was suggested that teacher training - preparation programs should assist general education teachers to learn and practice skills for effective collaboration. Moreover, Khairuddin et al. (2016) and Zagona et al. (2017) underlined the importance of adequate preparation and continuing support for pre-service and novice general education teachers to strengthen their skills, increase their feelings of self-efficacy, and subsequently benefit the students with disabilities.

As reported by Jurkowski et al. (2020) and Kirkpatrick et al. (2020) both resource teachers and classroom teachers highlighted the importance of more time to enhance their partnership. Furthermore, more assigned time should be consecrated to planning a common curriculum for all students, co-teaching, and assessing, thus teachers' schedules must be organized to allow for such shared time. Moreover, Kirkpatrick et al. (2020) also indicated that a good relationship based on communication, trust, and comfort between resource and classroom teachers, a positive attitude towards collaboration, and the effort to understand all students' needs are very important factors in order collaboration to be successful. The results offered by Bešić et al. (2017) suggest that special education teachers must be employed full-time by schools to decrease general teachers' burden and reinforce effective collaboration.

\section{Discussion}

This literature review reveals that besides the importance of teachers' partnerships, it is difficult to implement collaborative practices in and out of the classroom. The majority of authors covered in the review agree that general and special education teachers' collaboration forms are infrequent and insufficient. Even though the 
researchers demonstrate similarities in the content of teachers' cooperation such as co-planning and implementing students' educational programs, co-teaching, assessing, and discussing all students' issues, most of the studies' participants emphasize the poor collaborative behavior among them.

Nevertheless, there appears to be a tendency trend towards implementing collaborative practices as revealed by Jurkowski et al. (2020) and Kirkpatrick et al. (2020) and Mulholland \& O'Connor (2016) who demonstrate in their studies a more optimistic perspective of the teachers' cooperation. The success of these partnerships may be since the school board implemented a pilot project utilizing a coaching model (Jurkowski et al., 2020; Kirkpatrick et al., 2020). The observed increased collaboration (Mulholland \& O'Connor, 2016) could be attributed to school culture, which urges collaboration practices based on specific guidelines.

Discussing the challenges that negatively affect the collaboration between general and special education teachers, most of the authors agree on the lack of time to co-plan the lesson and assess the students together. Furthermore, especially classroom teachers mentioned insufficient training and administrative support as main constraints, which decrease the level of teachers' collaboration. Therefore, the preponderance of the authors (Bouillet, 2013) advocates the implementation of crucial factors for teachers' collaboration to be successful. The most common factor demonstrated in several studies is general and special education teachers' highly specified training in their respective domains, which will provide them the awareness to meet the needs of all students in inclusive classrooms. Additionally, more allocated time for co-planning lessons and co-teaching, communication, and positive attitudes towards collaboration are common elements regarding cooperation, which arise through the review of the aforementioned studies.

As most teachers demonstrated the need to collaborate with their colleagues to be more productive in the classroom for all students, future research should be focused on the exploration of all these factors which can contribute to the implementation of collaborative practices. Therefore, additional research must be conducted to increase knowledge in this field and develop efficient methods for the effective implementation of collaboration in inclusive schools.

\section{References}

Al-Natour, M., Amr, M., Al-Zboon, E., \& Alkhamra, H. (2015). Examining collaboration and constrains on collaboration between special and general education teachers in mainstream schools in Jordan. International Journal of Special Education, 30(1), 64-77.

Bešić, E., Paleczek, L., Krammer, M., \& Gasteiger-Klicpera, B. (2017). Inclusive practices at the teacher and class level: the experts' view. European Journal of Special Needs Education, 32(3), 329-345. https://doi.org/10.1080/08856257.2016.1240339

Bouillet, D. (2013). Some aspects of collaboration in inclusive education - Teachers' experiences. CEPS Journal, $3(2), 93-117$.

Conderman, G., \& Johnston-Rodriguez, S. (2009). Beginning teachers' views of their collaborative roles. Preventing School Failure: Alternative Education for Children and Youth, 53(4), 235-244.

Downing, J. E., \& Peckham-Hardin, K. D. (2007). Inclusive education: What makes it a good education for students with moderate to severe disabilities? Research and Practice for Persons with Severe Disabilities, 32(1), 16-30. https://doi.org/10.2511/rpsd.32.1.16

Friend, M., Cook, L., Hurley-Chamberlain, D., \& Shamberger, C. (2010). Co-teaching: An illustration of the complexity of collaboration in special education. Journal of Educational and Psychological Consultation, 20(1), 9-27. https://doi.org/10.1080/10474410903535380

Ghedin, E., \& Aquario, D. (2020). Collaborative Teaching in Mainstream Schools: Research with General Education and Support Teachers. International Journal of Whole Schooling, 16(2), 1-34.

Hamilton-Jones, B., \& Vail, C. O. (2013). Preparing Special Educators for Collaboration in the Classroom: PreService Teachers' Beliefs and Perspectives. International Journal of Special Education, 28(1), 56-68.

Hellmich, F., Hoya, F., Görel, G., \& Schwab, S. (2017). Unter welchen Voraussetzungen kooperieren Grundschullehrkräfte im inklusiven Unterricht? Eine Studie $\mathrm{zu}$ den Bedingungen der Kooperationsbereitschaft von Grundschullehrerinnen und -lehrern im inklusiven Unterricht. Empirische Sonderpädagogik, 1, 36-51.

Jurkowski, S., Ulrich, M., \& Müller, B. (2020). Co-teaching as a resource for inclusive classes: teachers' perspectives on conditions for successful collaboration. In International Journal of Inclusive Education. https://doi.org/10.1080/13603116.2020.1821449

Khairuddin, K. F., Dally, K., \& Foggett, J. (2016). Collaboration Between General and Special Education Teachers in Malaysia. Journal of Research in Special Educational Needs, 16(1), 909-913. https://doi.org/10.1111/1471-3802.12230

Kirkpatrick, L., Searle, M., Smyth, R. E., \& Specht, J. (2020). A coaching partnership: resource teachers and classroom teachers teaching collaboratively in regular classrooms. British Journal of Special Education, 47(1), 24-47. https://doi.org/10.1111/1467-8578.12296 
Mặrgặriţoiu, A. (2010). The Partnership in Inclusive School - Truth and Challenge. Educational Sciences Series, 62(2), $115-119$

Mavropalias, T. (2013). Evaluation of the Parallel Support program (PhD Thesis, University of Western Macedonia). http://hdl.handle.net/10442/hedi/30262

McKenzie, R. G. (2009). A national survey of pre-service preparation for collaboration. Teacher Education and Special Education: The Journal of the Teacher Education Division of the Council for Exceptional Children, 32(4), 379-393.

Mulholland, M., \& O'Connor, U. (2016). Collaborative classroom practice for inclusion: perspectives of classroom teachers and learning support/resource teachers. International Journal of Inclusive Education, 20(10), 1070-1083. https://doi.org/10.1080/13603116.2016.1145266

Papanikolaou, G. (2018). Indicators of quality of inclusive education programs for students with disabilities and/or special educational needs ( $\mathrm{PhD}$ Thesis, Aristotle University of Thessaloniki). http://hdl.handle.net/10442/hedi/44747

Pratt, S. (2014). Achieving symbiosis: Working through challenges found in co-teaching to achieve effective coteaching relationships. Teaching and Teacher Education, 41, 1-12. https://doi.org/10.1016/j.tate.2014.02.006

Rytivaara, A., Pulkkinen, J., \& de Bruin, C. L. (2019). Committing, engaging, and negotiating: Teachers' stories about creating shared spaces for co-teaching. Teaching and Teacher Education, 83, 225-235. https://doi.org/10.1016/j.tate.2019.04.013

Semon, S., Lane, D., Jones, P., \& Smith, S. M. (2020). Job-embedded professional development: implementing co-teaching practices in general education classrooms. In International Journal of Inclusive Education. https://doi.org/10.1080/13603116.2020.1821448

Solone, C. J., Thornton, B. E., Chiappe, J. C., Perez, C., Rearick, M. K., \& Falvey, M. A. (2020). Creating collaborative schools in the united states: A review of best practices. International Electronic Journal of Elementary Education, 12(3), 283-292. https://doi.org/10.26822/iejee.2020358222

Zagona, A. L., Kurth, J. A., \& MacFarland, S. Z. C. (2017). Teachers' views of their preparation for inclusive education and collaboration. Teacher Education and Special Education, 40(3), 163-178. https://doi.org/10.1177/0888406417692969 